\title{
Evaluation of Electric Energy Generation from Sound Energy Using Piezoelectric Actuator
}

\author{
Mohana Faroug Saeed Attia ${ }^{1}$, Afraa Ibraheim Mohmmed Abdalateef ${ }^{2}$ \\ ${ }^{1}$ Department of Physics, University of Dongola, Sudan \\ ${ }^{2}$ Collaborator Instructor University of Khartoum, Sudan
}

\begin{abstract}
This paper presents the work done on the conversion techniques and methodologies of converting sound energy to its electrical counterpart, and focuses on the future of this type of energy sources than wind energy, solar energy, and biogas. Also, it includes the increase in energy consumption due to ever growing number of electronic devices, and the harvesting energy from humans and using of piezoelectricity. In the experimental work, a piezoelectric generator lead zirconate titante (PZT actuator) is used to extract sound energy from the loudspeaker from various distances and then to convert this energy into electrical energy. The maximum voltage generated by the piezoelectric generator occurs when its resonant frequency is operating near the frequency of sound. The result shows that the maximum output voltage of $28.8 \mathrm{mV}$ rms was obtained with the sound intensity of $80.5 \mathrm{~dB}$ resonant frequency of $65 \mathrm{~Hz}$ at $1 \mathrm{~cm}$ distance in the first mode. In the second mode, the maximum output voltage of $94 \mathrm{~m} \mathrm{~V}_{\text {rms }}$ was obtained with the sound intensity of 105.7 dB at resonant frequency of $378 \mathrm{~Hz}$ at $1 \mathrm{~cm}$ which is larger than that of the first mode. However, for both modes, voltage decreases as distance increases.
\end{abstract}

Keywords: piezoelectric effect, sound energy, piezoelectric material, resonant frequency, PZT actuator, electricity

\section{Introduction}

The "law of conservation of energy" states that energy cannot be created nor be destroyed. Under the consideration of this law the technological giants have discovered numerous sources to extract energy from them and use it as a source of power for conventional use. ${ }^{[1]}$

There are various so called eco-friendly sources of energy that we have discovered till the present artificial era. Some of them are implemented to great extent under the suitable circumstances to overcome the short run of the energy due to technological boom that has led the energy needs to its apex. [2]

Solar energy is one in the list that came up with the wide range of applications such as solar heaters, solar cookers and it gained success due to its easy implementation. There are various other sources of renewable energy which includes harassing energy form wind, Biomass, water etc. ${ }^{[3]}$

Renewable energy sources such as hydropower, solar power and wind power require high financial investments but give lower power output with respect to its cost. Another source nuclear power plant gives a good source of power butthe initial setting up and maintains costs are higher than other renewable sources. In recent years, there has been growing interest in harnessing the power of mechanical vibrations and pressure to generate electricity.

Piezoelectric materials play a vital role in generating power which range is $\mu \mathrm{W}$ to $\mathrm{mW}$. It is one of the most interesting methods of obtaining the energy surrounding a system is to use piezoelectric materials. This deformations produced by different means are directly converted to electrical charge via piezoelectric effect. ${ }^{[4]}$
Piezoelectric materials have a crystalline structure that provides a unique ability to convert an applied mechanical strain into an electrical potential or vice versa. Our paper includes how to utilize the energy which is wasted, creates pollution to the environment. The sound energy of the moving train wheels which is nothing but pollution can be converted into electrical energy with the help of piezoelectric material or transducer. Then this electrical energy will be saved with the help of a rechargeable DC source. This energy can be used to run a train compartment's lights and fans and other necessary purpose. Here we discover the technology to generate electric power from sound of train wheels in which the system used is reliable and this technique will help conserve our natural resources. $^{[5]}$

\section{Sound Energy}

We all know sound energy is a mechanical energy which travel in the form of wave, mechanical wave that is an oscillation of pressure which need medium to travel i.e. it could not travel through vacuum as it need medium.

Through liquid and gas state sound is transmitted as longitudinal wave whereas through solid it could be transmitted as both longitudinal wave and transverse wave. ${ }^{[6]}$

Longitudinal waves are of alternating pressure deviation from the equilibrium pressure, causing local region of compression and rarefaction, while transverse wave (in solid) are waves of alternating shear and stress at right angle to the direction of propagation, fig 1 . When sound wave travel through a medium mater in that medium is periodically displaced and thus oscillates with sound wave. ${ }^{[7]}$

The sound wave displace back and forth between the potential energy of compression or lateral displacement strain of the matter and the kinetic energy of the oscillation. 


\section{International Journal of Science and Research (IJSR) \\ ISSN (Online): 2319-7064}

Index Copernicus Value (2013): 6.14 | Impact Factor (2014): 5.611

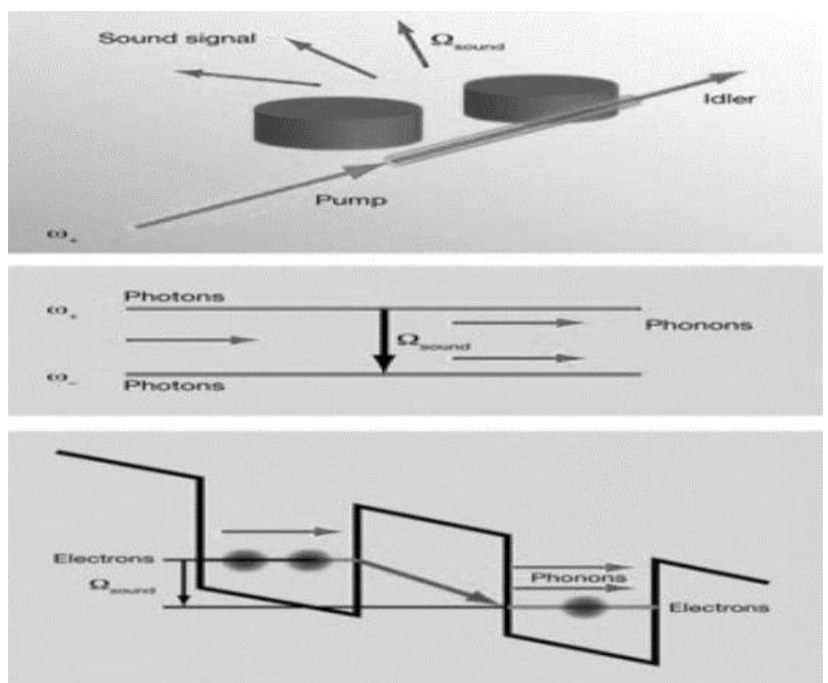

Figure 1: Propagation of Phonons in Sound

As sound energy is a mechanicalenergy it could be converted into electricity asmechanical energy could be converted into electricity bythe law of thermodynamics. Sound energy could beeasily converted into heat energy which could be easilyconverted into electricity but it is not highly efficient asthe loss in conversion will be more whereas the othermethod is converting sound energy to electricity by piezoelectric material, piezo electric materials are the crystalwhich converts mechanical strain to electric energy bysuch method, fig $2 .^{[8]}$

So we could see that sound is a form ofmechanical energy and according to third law ofthermodynamics mechanical energy could be convertedinto electric energy.

Sound that is perceptible by humans has frequencies from about $20 \mathrm{~Hz}$ to $20,000 \mathrm{~Hz}$. In air at standard temperature and pressure, the corresponding wavelengths of sound waves range from $17 \mathrm{~m}$ to $17 \mathrm{~mm} .^{[8]}$

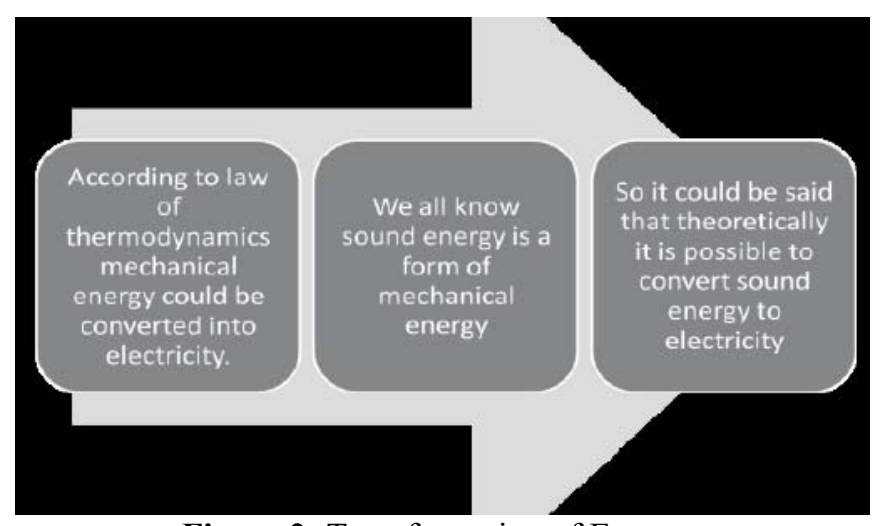

Figure 2: Transformation of Energy

\section{Practical Methods of Conversion}

In our day to day life we actually come across various devices that serve the same purpose that is they convert the sound to electrical signals. For example a microphone is an example of a transducer, a device that changes information from one form to another. Sound information exists as patterns of air pressure, the microphone changes this information into patterns of electric current. The recording engineer is interested in the accuracy of this transformation, a concept he thinks of as fidelity. ${ }^{[9]}$

The basic idea is that sound is mechanical wave. When sound travels through any medium then it disturbs the particles of that particular medium and these disturbances caused by the sound can be used to produce electricity.

The efficiency of the transducers and several such devices is quiet low and cannot be utilized for practical applications. Thus the major arena to focus is how we can increase the efficiency of the electricity produced by conversion of sound energy. Let us now see various methods by which we can make a system to convert sound to electrical energy. The basic parameters that determine the energy characteristics of noise are oscillation frequency and sound pressure.

Oscillation frequency is represented in Hertz $(\mathrm{Hz})$ and the sound pressure level is represented by decibels $(\mathrm{dB})$. Such electrical properties include Voltage (V), Current (I), resistance $(\mathrm{R})$ and power $(\mathrm{P})$. These quantities are related to each other as:

$\mathrm{I}=\mathrm{V} / \mathrm{R}$

$$
\mathrm{P}=\mathrm{V}^{2} / \mathrm{R}
$$

\subsection{Method 1}

The first method illustrates the use of the "faradays law of electromagnetic induction" which states that the induced electromotive force $(\mathcal{E})$ in any closed circuit is equal to the negative of the time rate of change of the magnetic flux $(\Phi)$ through the circuit.

$$
\varepsilon=-\mathrm{d} \Phi \mathrm{B} / \mathrm{dt}
$$

In this method we will place a very thin layer of diaphragm which will be fluctuated by the pressure created by the sound waves. Now we can attach a conductor to the diaphragm which will be placed between the magnetic poles. So when the diaphragm oscillates then the conductor will have magnetic flux around it change and as per the faradays law the (emf) is induced in the conductor causing the current to flow to conductor.

Generated voltage $(\mathrm{emf})=($ Velocity of Conductor $) \mathrm{X}$ (Magnetic Field) X (Length of Conductor).

As the frequency of the sound waves is high thus oscillations will be fast and considerable amount of electricity could be produced. But only limitation is that we require sound of very high decibels to generate usable quantity of electric power. ${ }^{[10]}$

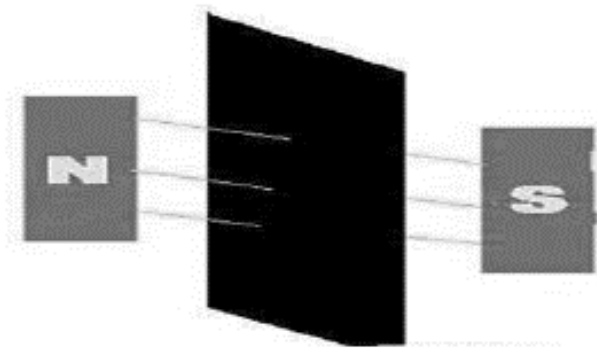

Figure 3: Diaphragm 


\section{International Journal of Science and Research (IJSR) \\ ISSN (Online): 2319-7064}

Index Copernicus Value (2013): 6.14 | Impact Factor (2014): 5.611

\subsection{Method 2}

In this method we could convert sound energy to heat energy as sound wave travel by oscillating the particles of the medium so when sound energy travel through the medium it will disturbs the particle of the medium these disturbance created by sound will be used to convert it into heat energy as when the particles of the medium will be pushed by the sound wave it will collides with adjacent particle of the medium this collision will result production of heat energy the production of heat energy will be more in the denser medium so for more heat production we will need a material with very high density. This heat energy will be converted into electricity. ${ }^{[11]}$

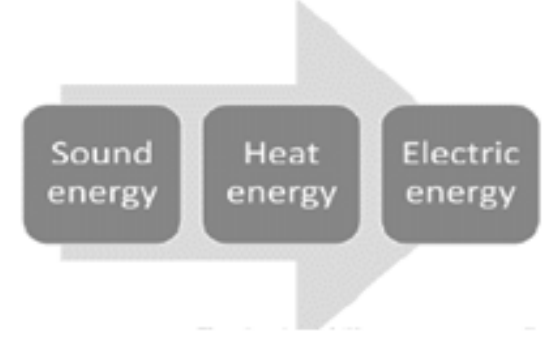

Figure 4: converting sound energy to electricity

This method is less efficient due to more energy losses taking place while conversion of sound energy to heat energy and then heat energy to electric energy then the other methods. As here the conversion is done two times .you may think that according to Newtown's law energy can't be created nor destroyed it could be only converted from one form to another .So while converting sound energy to heat energy there will be some loss of sound energy as some of the sound energy would be converted into another form also while converting from heat energy to electric energy all energy wouldn't be converted into electric energy some of the heat energy would get converted into another form of energy. And here as our main focus is to convert sound energy to electric energy so conversion into other form of energy is loss of energy for us. ${ }^{[1]}$

\subsection{Method 3}

Converting sound energy to electricity by Piezo electric material (piezo electric materials are the crystal which convert mechanical strain to electric energy).

\subsubsection{Piezoelectric Materials}

Piezo electric materials are transducers its crystals could convert mechanical strain to electricity, the crystals are formed naturally e.g. quartz, bone, DNA whereas artificially $\mathrm{ZnO}$, lithium niobatet Lead Metaniobate the sound energy could be converted into electricity using piezo electric material. Let us see the properties of piezo electric material. $^{[12]}$

\subsubsection{Piezoelectric Material andThere Properties}

Certain single crystal materials exhibit the following phenomenon: when the crystal is mechanically strained, (here sound energy) or when the crystal is deformed by the application of an external stress, electric charges appear on thecrystal surfaces, and when the direction of the strain reverses, the polarity of the electric charge is reversed. This is called the direct piezo electric effect, and the crystals that exhibit it are classed as piezoelectric crystal. ${ }^{[12]}$

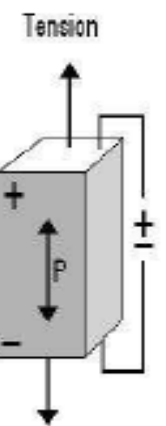

Compression
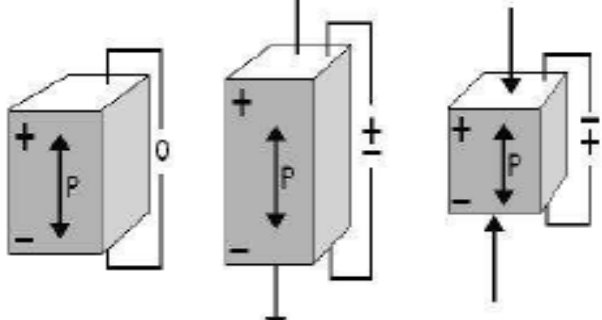

Figure 5: The direct piezoelectric effect

Inversely, when a piezoelectric crystal is placed in an electric field, or when charges are applied by external means to its faces, the crystal exhibits strain, i.e. the dimensions of the crystal Changes. When the direction of the applied electric field is reversed, the direction of the resulting strain is reversed. This is called the inverse piezo electric effect. (See Fig. 6).
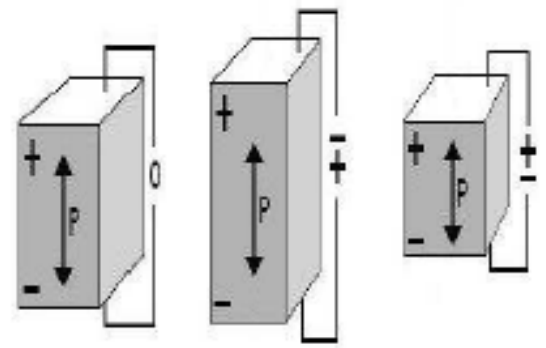

Figure 6: The inverse piezo electric effect

So it could be seen that when the sound energy is applied to the piezoelectric material it create strain in the crystal then it reverse it and the strain is converted into electric energy .This direct piezo electric effect property of an piezo electric material could be used for making the device to convert sound energy to electric energy. ${ }^{[12]}$

\section{Piezoelectric Crystal}

\subsection{Energy from Humans}

The human body contains enormous quantities of energy, for e.g. an average adult has a one-ton battery in the form of fats in present in the body. This energy is used as fuels for all activities. Piezoelectric effect can be used to generate electricity using such body energies to run smaller gadgets which consume less power. ${ }^{[12]}$

\subsection{Present Use of Technology}

Tiles made up of many layers of rubber sheeting, to absorb the vibrations and ceramic; underneath piezoelectric crystals are placed which can be used to generate electricity by movements on them. When such tiles are installed in locations where large crowd movements are expected like in Railway \& Bus stations, Airports, Malls etc., and a person steps on them, than by piezoelectric effect small charge is built up on surface of crystals. 


\section{International Journal of Science and Research (IJSR) \\ ISSN (Online): 2319-7064}

Index Copernicus Value (2013): 6.14 | Impact Factor (2014): 5.611

Though energy generated by one person would be too less but if number of steps on such tiles increase than energy produced by it would increase too. One more way to increase energy by use of such tiles is to increase pressure on them i.e. to use them for road construction. When a person steps on such tiles piezoelectric crystal underneath it experiences mechanical stress which creates electric charge built up on crystal's surface which can be collected by use of electrodes. Such energy can be stored in capacitors and power can be channeled to energy deficient regions. ${ }^{[13]}$

Japan has already started experimenting use of piezoelectric effect for energy generation by installing special flooring tiles at its capitals' two busiest stations. Tiles are installed in front of ticket turnstiles. Thus every time a passenger steps on mats, they trigger a small vibration that can be stored as energy.

Energy thus generated by single passenger multiplied by many times over by the 400,000 people who use Tokyo station on an average day, according to East Japan Railway, which generates sufficient energy to light up electronic signboards. ${ }^{[13]}$

An average person weighing $60 \mathrm{~kg}$ will generate only 0.1 watt in the single second required to take two steps across the tile, but when they are covering a large area of floor space and thousands of people are stepping or jumping on them, then significant amount of power can be generated. This energy created is sufficient to run automatic ticket gates and electronic displays, constructing special types of roads that generates electricityjust by driving over them is next step towards use ofpiezoelectric crystals. The system works by embedding tinypiezoelectric crystals into the road,when cars drive over suchroads crystals embedded in them squeeze and thus generate asmall electrical charge. Though small charge is generated bysingle car but $1 \mathrm{~km}$ stretch of such road could generate around $400 \mathrm{~kW}$-enough to run eight small cars.

According to the EnvironmentalTransport Association (ETA), if such system was installed onevery stretch of British motorway it would generate enoughenergy to run 34,500 small cars. Certain vehicles could thus bepowered entirely by road on which they drive. ${ }^{[14]}$

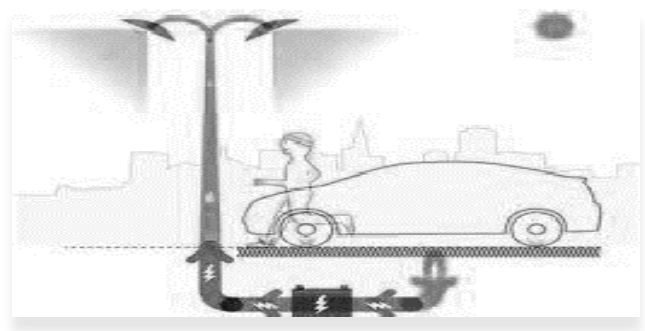

Figure 7: Specially designed road which generates electricity.

\section{Material and Method}

This section is devoted for the equipment and instruments used in relating the frequency and output voltage, for the system generate electricity test.
The reading is collected at Riyadh City in Saudi Arabia, the specification of the generator power system used the statistical beside mathematical techniques are presented in this section. The reading collected and relationship between frequency and output voltage are displayed graphically.

\subsection{Instrumentation}

The electricity generation experiment was done by using a sound wave convertor extract sound wave energy from the loudspeaker. In this study, PZT piezoelectric actuator, shown in fig (8), is used as a sound wave energy convertor.

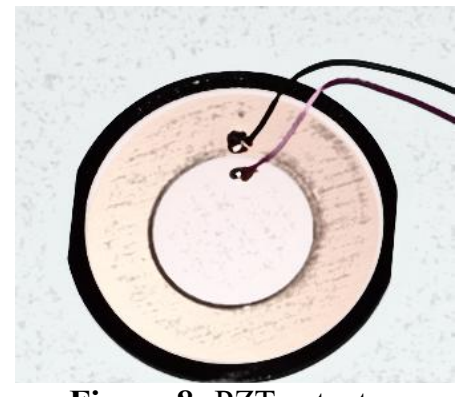

Figure 8: PZT actuator

\subsubsection{Design, Coast and Method of Work}

This is a speaker with piezoelectric actuator formed from lead zirconate titante (PZT) ceramic, the PTZ is the white disk in the center of a brass diaphragm. The PTZ coated with a thin silver layer on the top as one electrode, and the brass is used as the bottom electrode. When the generated sound wave from the motion of the diaphragm in the loudspeaker is applied to the piezoelectric actuator, a pressure wave is produced that hits the piezoelectric actuator. Sufficient energy from this generated sound can deform the piezoelectric actuator and generate electricity. This electricity, which is in the form of voltage signal, is measured using an oscilloscope. The device has been bought about $30 \$$.

To verify the resonant frequency of the piezoelectric actuator, the frequency of the sound wave used is increased gradually from $50 \mathrm{~Hz}$ to $70 \mathrm{~Hz}$ for the first mode, and from $360 \mathrm{~Hz}$ to $390 \mathrm{~Hz}$ for the second mode. During resonance, the maximum conversion produces the highest voltage as a result of the piezoelectric effect, also the effect of the distance between the sound source and the piezoelectric during resonance is investigated.

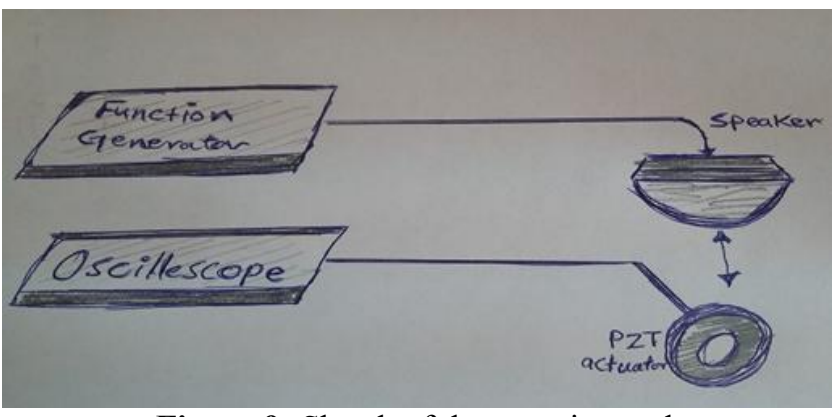

Figure 9: Sketch of the experimental 


\section{International Journal of Science and Research (IJSR) \\ ISSN (Online): 2319-7064}

Index Copernicus Value (2013): 6.14 | Impact Factor (2014): 5.611

\subsection{Data Collection: Criteria and Requirement}

The following study was carried out as applied experimental study in the realm of applied physics science inclusively as renewable energy.

The resonant frequency

$$
f_{0}=(1 / 2 \pi)\left(k_{T} / m_{\text {eff }}\right)^{1 / 2}
$$

Where: $f_{0}=$ resonant frequency of actuator $[\mathrm{Hz}]$

$\mathrm{k}_{\mathrm{T}}=$ piezo actuator stiffness $[\mathrm{N} / \mathrm{m}]$

$\mathrm{m}_{\text {eff }}=$ effective mass (about $1 / 3$ of the mass of the ceramic stack plus any installed end pieces) $[\mathrm{kg}]$

The small-signal capacitance of a stack actuator can be estimated by:

$$
C=n . \varepsilon_{33} . T . A / d_{s}
$$

Where:

$\mathrm{C}=$ capacitance $[\mathrm{F}(\mathrm{As} / \mathrm{V})]$

$\mathrm{n}=$ number of layers $=\mathrm{I}_{0} / \mathrm{d}_{\mathrm{s}}$

$\varepsilon_{33} \mathrm{~T}=$ dielectric constant $[\mathrm{As} / \mathrm{Vm}]$

$\mathrm{A}=$ electrode surface area of a single layer $\left[\mathrm{m}^{2}\right]$

$\mathrm{d}_{\mathrm{S}}=$ distance between the individual electrodes (layer-

thickness) [m]

$\mathrm{I}_{0}=$ actuator length. $^{[15]}$

To a chive these objectives, the research was carried at Riyadh City - Saudi Arabia, during the period from January 2015 to April 2015. When reading are subjected to experiment test information such as, distance from source, sound intensity, resonant frequency and output voltage are collected.

To obtained data related to frequency were plotted versus output voltage in first and second mode. The significant relationships are examined by using Statistical Package Social Science version 20(SPSS - 20).

\section{Results and Discussion}

\section{Table and Graph}

\section{Table 1, First Mode $(50-70) \mathrm{Hz}$}

Table 1: Resonant frequency in the first mode

\begin{tabular}{|c|c|c|c|}
\hline $\begin{array}{c}\text { Distance } \\
(\mathrm{cm})\end{array}$ & $\begin{array}{c}\text { Resonant } \\
\text { Frequency } \\
(\mathrm{Hz})\end{array}$ & $\begin{array}{c}\text { Sound } \\
\text { Intensity } \\
(\mathrm{dB})\end{array}$ & $\begin{array}{c}\text { Output voltage } \\
\left(\mathrm{mV}_{\text {rms }}\right.\end{array}$ \\
\hline 1 & 65 & 80.5 & 28.8 \\
\hline 4 & 66 & 77.4 & 15.6 \\
\hline 7 & 69 & 76 & 10.7 \\
\hline
\end{tabular}

Table 2, Second Mode (369 - 390) Hz

Table 2: Resonant frequency in the second mode

\begin{tabular}{|c|c|c|c|}
\hline $\begin{array}{c}\text { Distance } \\
(\mathrm{cm})\end{array}$ & $\begin{array}{c}\text { Resonant } \\
\text { Frequency } \\
(\mathrm{Hz})\end{array}$ & $\begin{array}{c}\text { Sound } \\
\text { Intensity } \\
(\mathrm{dB})\end{array}$ & $\begin{array}{c}\text { Output } \\
\text { voltage } \\
\left(\mathrm{mV}_{\mathrm{rms}}\right.\end{array}$ \\
\hline 1 & 378 & 105.5 & 94 \\
\hline 4 & 379 & 100.7 & 65.7 \\
\hline 7 & 381 & 90.6 & 35 \\
\hline
\end{tabular}

\section{Graph: First mode $(50-70) ~ H z$}

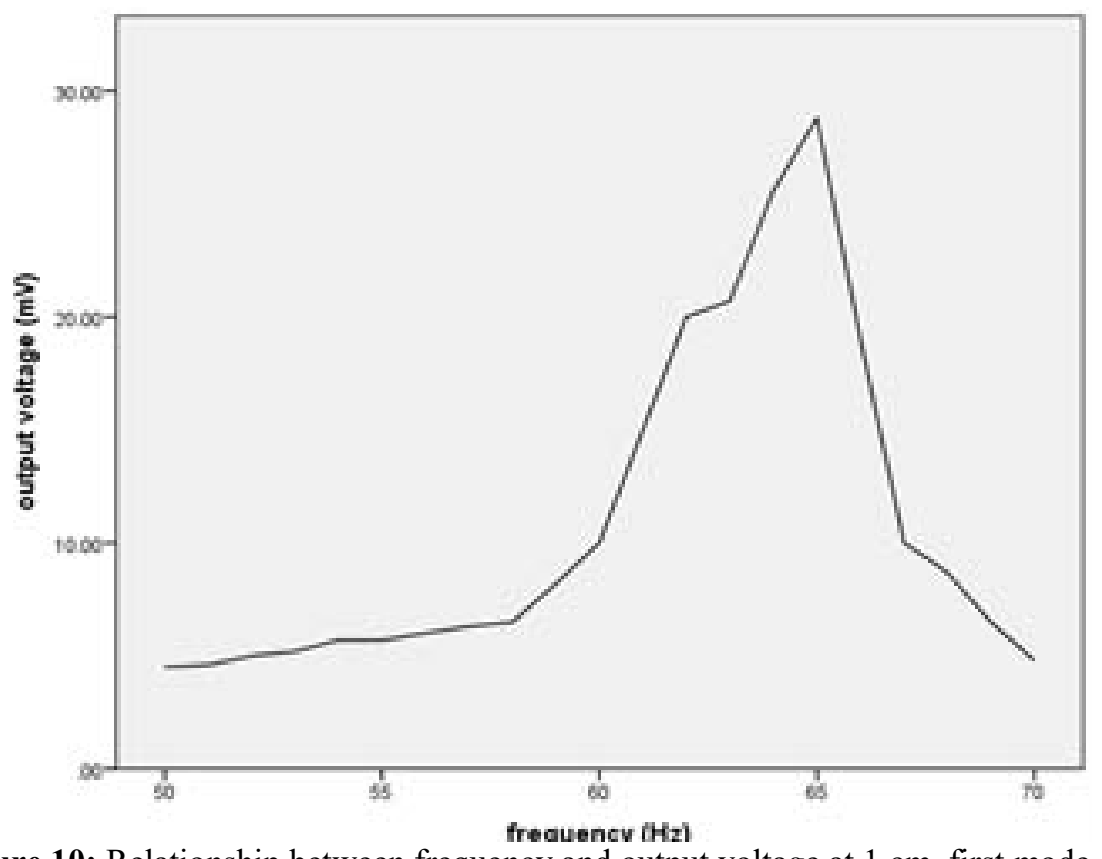

Figure 10: Relationship between frequency and output voltage at $1 \mathrm{~cm}$, first mode. 


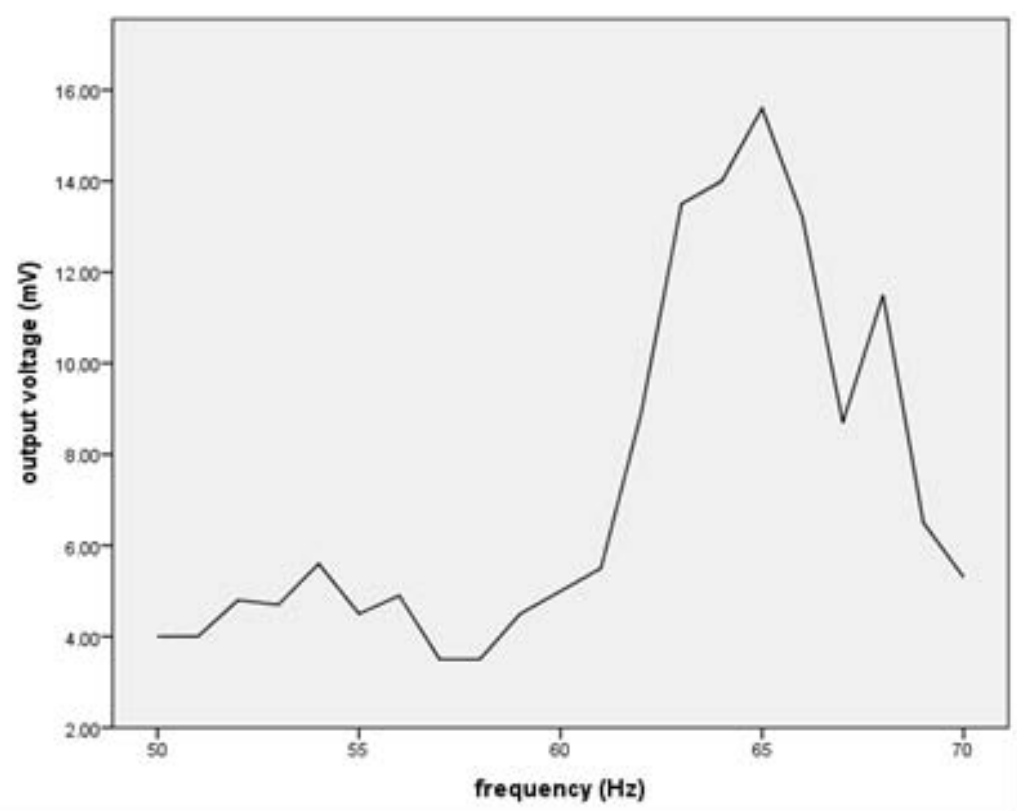

Figure 11: Relationship between frequency and output voltage at $4 \mathrm{~cm}$ first mode.

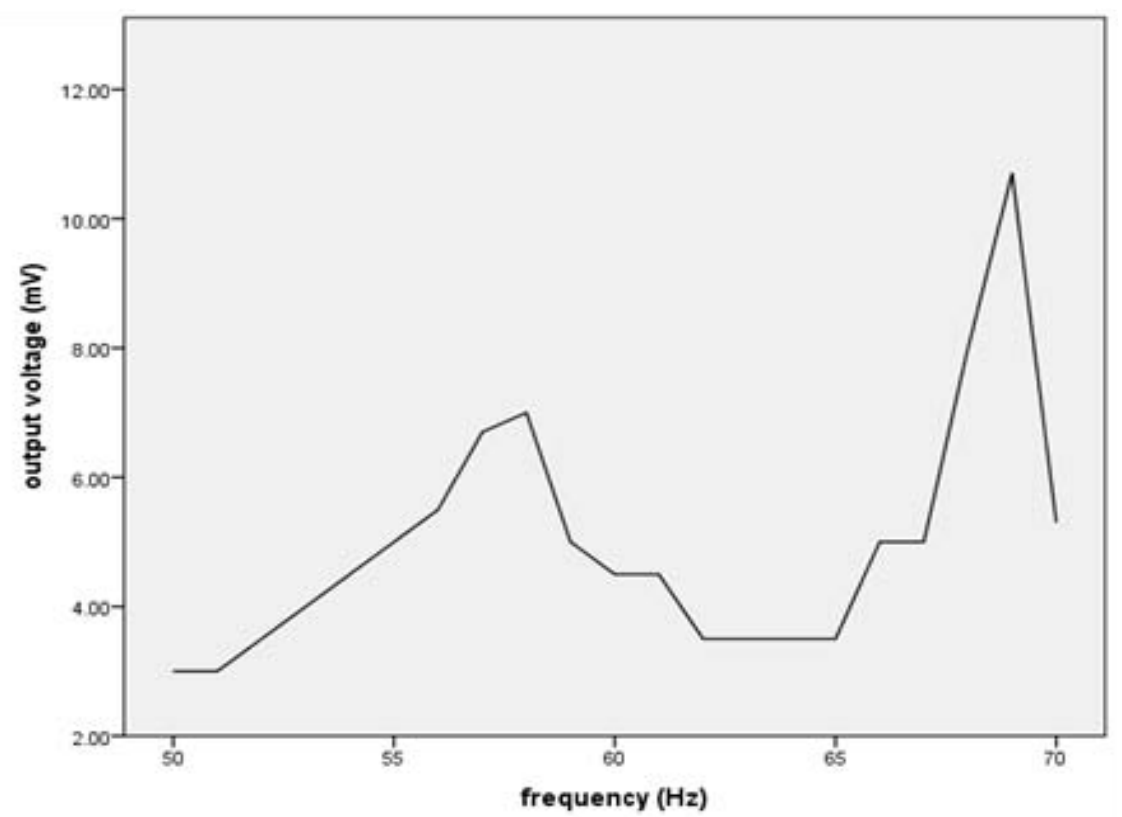

Figure 12: Relationship between frequency and output voltage at $7 \mathrm{~cm}$ first mode.

Graph: Second mode $(360-370) \mathrm{Hz}$

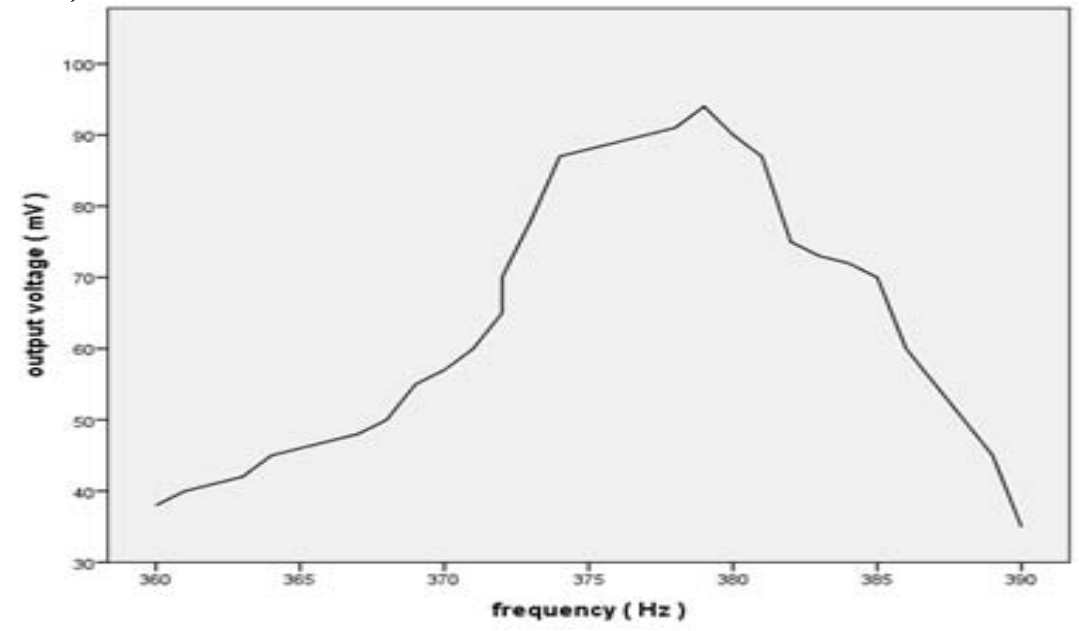

Figure 13: Relationship between frequency and output voltage at $1 \mathrm{~cm}$, second mode.

Volume 5 Issue 1, January 2016

www.ijsr.net 


\section{International Journal of Science and Research (IJSR) \\ ISSN (Online): 2319-7064}

Index Copernicus Value (2013): 6.14 | Impact Factor (2014): 5.611

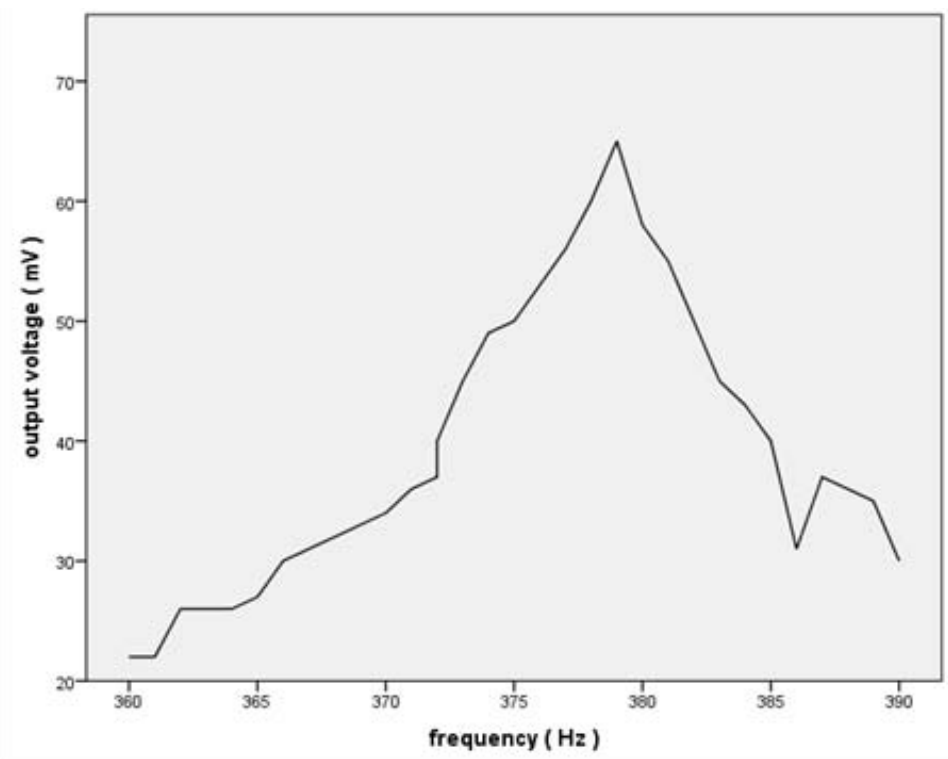

Figure 14: Relationship between frequency and output voltage at $4 \mathrm{~cm}$, second mode.

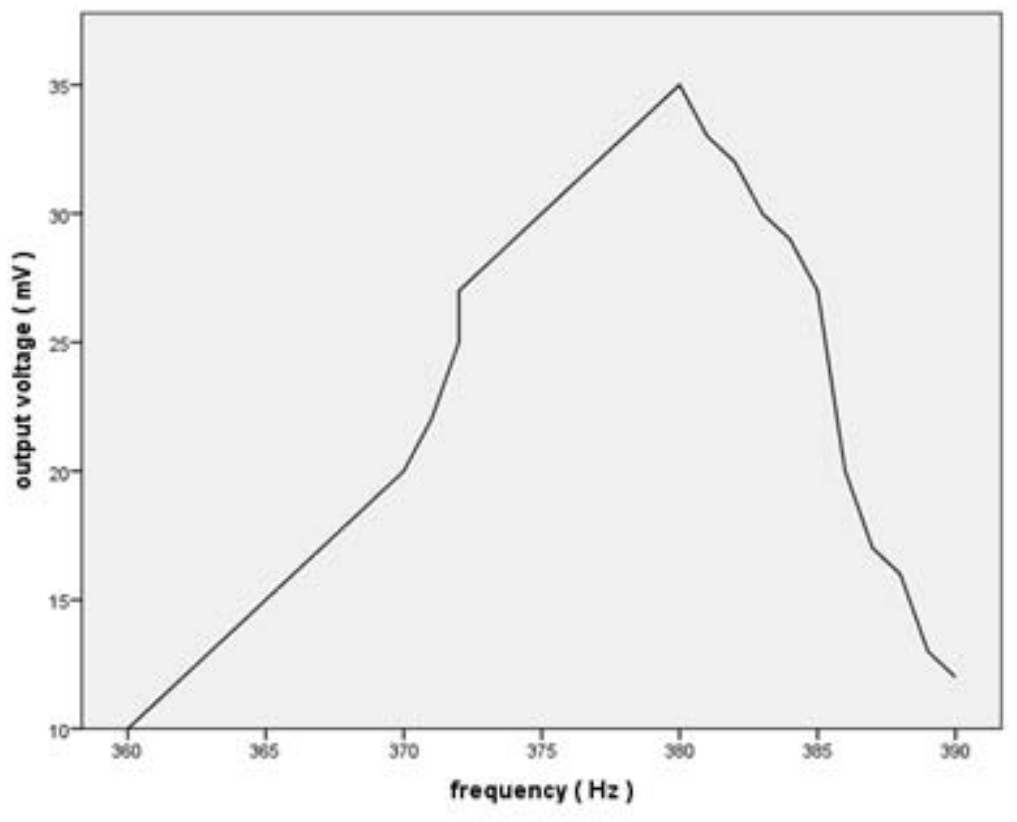

Figure 15: Relationship between frequency and output voltage at $7 \mathrm{~cm}$, second mode.

\section{Discussion}

Table (1) and figs. (10, 11 and 12) the resonant frequencies obtained are $65 \mathrm{~Hz}, 66 \mathrm{~Hz}$ and $69 \mathrm{~Hz}$ at 1,4 and $7 \mathrm{~cm}$, respectively. In the second mode, as shown in Table (2), the resonant frequencies occur at $378 \mathrm{~Hz}, 379 \mathrm{~Hz}$ and $381 \mathrm{~Hz}$ at $1,4,7 \mathrm{~cm}$, respectively.

Sound intensity is measured at different distances, and the results are $80.5 \mathrm{~dB}$ at $1 \mathrm{~cm}, 77.5 \mathrm{~dB}$ at $4 \mathrm{~cm}$ and $76 \mathrm{~dB}$ at 7 $\mathrm{cm}$. In the second mode, the sound intensities obtained are $105.5 \mathrm{~dB}$ at $1 \mathrm{~cm}, 100.7 \mathrm{~dB}$ at $4 \mathrm{~cm}$ and $90.6 \mathrm{~dB}$ at $7 \mathrm{~cm}$. These results show that when the piezoelectric actuator is placed near the sound source, the pressure gradient of the sound wave is at maximum, thus, for both modes, sound intensity increases as the distance decreases.
The output voltage obtained from the experiment shows that at the resonant frequency of each state, $28.8 \mathrm{mV}_{\mathrm{rms}}$ at $1 \mathrm{~cm}$, $15.6 \mathrm{~m} \mathrm{~V}$ rms at $4 \mathrm{~cm}$ and $10.7 \mathrm{mV}_{\text {rms }}$ at $7 \mathrm{~cm}$ are produced in the first mode, as in figs. (10, 11 and 12).

Figs. $(13,14$ and 15) shows that in the second mode, the voltage produced are $94 \mathrm{mV}_{\text {rms }}$ at $1 \mathrm{~cm}, 65.7 \mathrm{mV}_{\text {rms }}$ at $4 \mathrm{~cm}$ and $35 \mathrm{mV}_{\text {rms }}$, which are higher than those produced in the first mode. When the piezoelectric actuator is placed near the speaker, the pressure gradient and frequency of sound wave are higher, thus a considerable amount of energy is applied to increase the deformation of the piezoelectric actuator. As a result, maximum voltage is produced by the piezoelectric. 


\section{International Journal of Science and Research (IJSR) \\ ISSN (Online): 2319-7064}

Index Copernicus Value (2013): 6.14 | Impact Factor (2014): 5.611

\section{Conclusion}

- Sound energy is a mechanical energy so according to law of thermodynamics mechanical energy could be converted into electric energy.

- Sound energy could be converted by different methods:

- Method 1 by creating apparatus using curtain (diphagram) magnet and conductor

- Methods 2 by converting Sound energy to heat energy and then heat

- Energy to electric energy.

- Method 3 by using transducers such as piezoelectric material which converts mechanical strain to electric energy.

- Piezo electric crystals are the crystals which converts mechanical strain to electric energy.

- The strain applied to piezo electric material by sound energy could be converted into electricity.

- Use of piezoelectric crystals has being started and positive results are obtained. With further advancement in field of electronics, better synthesized piezoelectric crystals and better selection of place of installations, more electricity can be generated and it can be viewed as a next promising source of generating electricity.

- This study therefore show that the proposed technique used to harvest sound wave energy is relevant and has great potential in terms of converting free energy into useful energy.

- Sound intensity is an important parameter to effectively extract and convert energy using a piezoelectric actuator.

- Results show that less voltage is produced as distance increases.

\section{References}

[1] V. K. Vijay and H. R. Garg, " Renewable Energy and Environment for Sustainable Development ", 2009

[2] William Kemp, "Renewable Energy Handbook", AZ text Press, 2003.

[3] K. C. Singal, Rakesh Ranjan, D. P. Kothari, "Renewable Energy Sources and Emerging Technologies," PHI Learning Ltd. India, 2011.

[4] Antonio Arnau "Piezoelectric Transducers and Applications", Springer - Verlag Berlin Heidelberg, German and Spain, 2008.

[5] Md. Mostaqim Billah Arnab, Shah Md. Rahmot Ullah, Md. Ashraful Alam, Raton Kumar, S M. Forhadul Alam and Anik Paul Mish, "Generation of Electrical Energy Using Piezoelectric Material from Train Wheels: Bangladesh Perspective", IEEE

[6] ISSN978-4799-6062-0/14/\$31.00, 2014.

[7] J. Duncan Glover, Mulukutla S. Sarma and Thomas Overbye, "Power System Analysis and Design," CENGAGE Learning, USA, 2011.

[8] Simon M. Sze and Kwok K. Ng "Physics of Semiconductor Devices", John Wiley \& Sons, Inc. Press, New York and London, 2006.

[9] Bernard Jaffe, W. R. Cook and H. Jaffe "Piezoelectric Ceramic," Academic Press London and New York, 1971.

[10]Alankrit Gupta, Vivek Goel and Vivek Yadav, “ Conversion of Sound to Electric Energy "International
Journal of Scientific \& Engineering Research ISSN 2229-5518, Volume 5, Issue 1, January 2014.

[11] Jos Arrillaga and Neville R. Watson, "Power System Harmonics", John Wiley \& Sons Ltd. England, 2003.

[12] Shalabh Rakesh Bhatnagar " converting sound energy to electric energy" International Journal of Emerging Technology and Advanced Engineering ISSN 22502459, Volume 2, Issue 10, October 2012.

[13]Henry Frank Tiersten "Linear Piezoelectric Plate", Springer Heidelberg Dordrecht London and New York, 1969.

[14] Tanvi Dikshit, Dhawal Sheerivastava, Abhijeet Gorey, Ashish Gupta, Parag Parandkar and Sumant Katiyal, "Energy Harvesting via Piezoelectricity" BVICAMs International Journal of Information Technology, 2010.

[15] Pramathesh. T and Ankur. S "Piezoelectric Crystals: Future Source of Electricity'International Journal of Scientific Engineering and Technology ISSN 2277 1581, Volume 2, Issue 4, April 2013.

[16]Zhu D, Beeby SP, "Energy Harvesting Systems Principles, Modeling and Applications", Springer New York, 2011. 